\title{
Erratum to: Ultraviolet Light-Emitting Diodes for Water Disinfection
}

\author{
Marlene A. Lange, Tim Kolbe and Martin Jekel
}

\section{Erratum to:}

Chapter 10 in: M. Kneissl and J. Rass (eds.), III-Nitride Ultraviolet Emitters, Springer Series in Materials Science 227, DOI 10.1007/978-3-319-24100-5_10

\section{Erratum DOI 10.1007/978-3-319-24100-5_16}

The original version of the book was inadvertently published with an incorrect spelling of the chapter author's name as "Martina A. Lange" in the table of contents, list of contributors, and chapter opening page. The correct spelling of the author's name should read as "Marlene A. Lange".

The updated original online version for this chapter can be found at DOI 10.1007/978-3-319-24100-5_10

\section{M.A. Lange - M. Jekel}

Technische Universität Berlin, Fachgebiet Wasserreinhaltung,

Sekr. KF4, Straße des 17 Juni 135, 10623 Berlin, Germany

e-mail: marlange@posteo.de

M. Jekel

e-mail: martin.jekel@tu-berlin.de

T. Kolbe $(\bowtie)$

Ferdinand-Braun-Institut, Leibniz-Institut für Höchstfrequenztechnik,

Gustav-Kirchhoff-Straße 4, 12489 Berlin, Germany

e-mail: tim.kolbe@fbh-berlin.de 